\title{
Zero Energy Building - A review of definitions and calculation methodologies
}

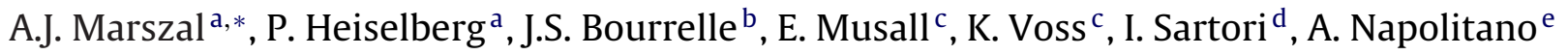 \\ a Department of Civil Engineering, Aalborg University, Sohngaardsholmsvej 57, DK-9000 Aalborg, Denmark \\ ${ }^{\mathrm{b}}$ Department of Architectural Design, History and Technology, Norwegian University of Science and Technology, Alfred Getz vei 3, NO-7491 Trondheim, Norway

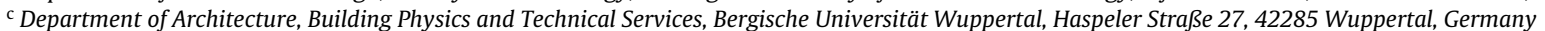 \\ d SINTEF Building and Infrastructure, 124 Blindern, N-314 Oslo, Norway \\ e EURAC Research, Institute for Renewable Energy, Viale Druso n1, 39100 Bolzano, Italy
}

\section{A R T I C L E I N F O}

\section{Article history:}

Received 19 October 2010

Accepted 14 December 2010

\section{Keywords:}

Zero Energy Building

Zero Emission Building

Net Zero Energy Building

ZEB definition

Energy calculation methodologies

\begin{abstract}
A B S T R A C T
The concept of Zero Energy Building (ZEB) has gained wide international attention during last few years and is now seen as the future target for the design of buildings. However, before being fully implemented in the national building codes and international standards, the ZEB concept requires clear and consistent definition and a commonly agreed energy calculation methodology. The most important issues that should be given special attention before developing a new ZEB definition are: (1) the metric of the balance, (2) the balancing period, (3) the type of energy use included in the balance, (4) the type of energy balance, (5) the accepted renewable energy supply options, (6) the connection to the energy infrastructure and (7) the requirements for the energy efficiency, the indoor climate and in case of gird connected ZEB for the building-grid interaction. This paper focuses on the review of the most of the existing ZEB definitions and the various approaches towards possible ZEB calculation methodologies. It presents and discusses possible answers to the abovementioned issues in order to facilitate the development of a consistent ZEB definition and a robust energy calculation methodology.
\end{abstract}

(c) 2011 Elsevier B.V. All rights reserved.

\section{Introduction}

The Zero Energy Building (ZEB) concept is no longer perceived as a concept of a remote future, but as a realistic solution for the mitigation of $\mathrm{CO}_{2}$ emissions and/or the reduction of energy use in the building sector. The increasing number of ZEB demonstration projects [1-7] and research interest in the field [8-11] internationally highlights the growing attention given to ZEBs. Goals for the implementation of ZEBs are discussed and proposed at the international level e.g. in the USA within the Energy Independence and Security Act of 2007 (EISA 2007) and, at the European level within the recast of the Directive on Energy Performance of Buildings (EPBD) adopted in May 2010. The EISA 2007 authorizes the NetZero Energy Commercial Building Initiative to support the goal of net zero energy for all new commercial buildings by 2030. It further specifies a zero-energy target for $50 \%$ of U.S. commercial buildings by 2040 and net zero for all U.S. commercial buildings by 2050 [12]. The EPBD establishes the 'nearly zero energy building' as the building target from 2018 for all public owned or occupied by public authorities buildings and from 2020 for all new buildings, [13]. By setting these objectives, at the European level the nearly ZEBs should be reality in just eight years.

\footnotetext{
* Corresponding author. Tel.: +45 9940 8587; fax: +45 99408552.

E-mail address: ajm@civil.aau.dk (A.J. Marszal).
}

Despite the clear international goals and the international attention given to the ZEBs two major challenges need to be met before full integration of the ZEB concept into national building codes and/or international standards. This includes, in particular, the adaptation of a common and unambiguous definition and the development of a supporting methodology for computing the energy balance. In the existing literature the Zero Energy Building concept is described with a wide range of terms and expressions and a number of distinct approaches towards ZEB definitions can be distinguished. The lack of a commonly agreed ZEB definition is already widely discussed on the international level [8]. The need for a robust calculation methodology has gained attention with the growing number of ZEB projects and thus the interest in how the 'zero' balance is computed. Some countries are on their way to embrace the ZEBs in their national building codes, however no standardized calculation procedure yet exists and most of the calculations are just voluntary proposals developed for a particular ZEB case.

As mentioned, the ZEB concept is the future international goal, however in order to progress with this aim there is a genuine demand for a commonly agreed framework for definition and calculation methodology. This paper first gives an overview of existing ZEB definitions with highlighting the most important aspects which should be discussed before developing new ZEB definitions. Secondly, it presents various approaches towards possible ZEB calculation methodologies. And finally, the paper attempts to 
provide some recommendations on the direction the development of a future ZEB definition and calculation methodology should proceed.

\section{ZEB definitions - review of literature and calculation methodologies}

The Zero Energy Building is a complex concept with number of already existing approaches that spotlight different aspects of ZEB. Furthermore, the energy balance calculation of a building equipped with on-site and/or off-site renewable energy generation systems and/or interacting with the utility grid and striving to fulfil 'zero' goal is not an easy task. Moreover, with no clear standardized support for 'zero' calculating methodology. Some voluntary environmental assessment methods like LEED [14] or BREEAM [15] do exist, yet they have much wider scope than the current frameworks for the ZEBs. Therefore, if ZEB is seen as a future target for the buildings, it is a key issue to develop a physically convincing, robust and communicable calculation methodology that reflects the concept and facilitate the work of both architects and engineers in designing Zero Energy Buildings.

The autonomous, off-grid ZEBs have not gained big international attention and are rather perceived as a one of the intermediate steps on the path towards grid connected, net ZEBs [16-18]. Therefore, the calculation methodologies included in this paper reflects the energy calculations of the net ZEB.

The study of various approaches for computing net ZEB balance is based on the methodologies proposed by participating researchers of the IEA SHC Task 40/ECBCS Annex 52 'Towards Net Zero Energy Solar Building', Table 1 Meth. 1-11 and the methodology suggested by Hernandez and Kenny [19] Table 1 Meth. 12. It should be noticed that the energy calculations collected within IEA SHC Task 40/ECBCS Annex 52 are just proposals without peer review or published sources. Table 1 provides an overview of the most important features of each methodology with regards to metric, period and type of the balance, types of energy use included, renewable supply options, primary energy and $\mathrm{CO}_{2}$ factors and unique features.

The following chapter presents both the diversity of ZEB definitions found in the existing literature and proposed energy calculation methodologies for these buildings. The headings emphasize the questions that should be clearly answered before defining Zero Energy Buildings.

\subsection{Metric of the balance}

The applied unit for the 'zero' balance can be influenced by a number of measures; therefore more the one unit can be used in the definition and/or calculation methodology. These can be i.e. the final also called delivered, end-use or un-weighted energy, primary energy, $\mathrm{CO}_{2}$ equivalent emissions, exergy, the cost of energy or other parameters defined by national energy policy.

\subsubsection{Literature review}

Torcellini et al. [16] indicate that the unit applied in the ZEB definition can be influenced by (1) the project goals, (2) the intentions of the investor, (3) the concerns about the climate and green house gas emissions and (4) the energy cost. Therefore, they propose four different ZEB definitions: site ZEB, source ZEB, emissions ZEB and cost $Z E B$, respectively. The authors point out advantages and disadvantages of each of the definition i.e. easy implementation of 'zero site energy' and 'zero energy costs' definition, more international and not regional feature of 'zero source energy' definition and calculation complexity of 'zero energy emission' definition. The proposed distinction between different metrics is brought up and further discussed in a number of publications [4,20-23]. Kilkis [20] states that the metric of the balance in the ZEB definition should address both the quantity as well as the quality of energy, if we want to assess the complete building's impact on the environment. Therefore, he proposes a new definition for the term ZEB, in particular a net zero exergy building and defines it as 'a building, which has a total annual sum of zero exergy transfer across the building-district boundary in a district energy system, during all electric and any other transfer that is taking place in a certain period of time'. Mertz et al. [24] and Laustsen [25] distinguish only two units of the balance: emissions and energy, however, without specifying delivered or primary energy. The definition of 'Near Zero Energy Building' from the EPBD [13] is clear and uses the primary energy as the metric for the energy balance.

\subsubsection{Applied methodologies}

Based on Table 1, the primary energy clearly is the most favoured metric of the net ZEB balance. This is in line with the latest EPBD recast [13] and common practice in many building energy calculations methodologies. Three methodologies adopt more than one unit, possibly due to the fact that ZEB can state also for zero emission building and/or to emphasize lack of commonly agreed metric.

\subsection{Period of the balance}

The period of time over which the building calculation is performed can vary very much. It can be an exhaustive full life cycle of a building or the operating time of the building (e.g. 50 years) or very commonly used annual balance or applied in special situations a seasonal or monthly balance.

\subsubsection{Literature review}

In the existing literature on the ZEB concept the annual balance is the most favoured balancing period [4,21,24,26-29]. Hernandez and Kenny [19] acknowledge that the full life cycle of the building could be more appropriate period for the energy balance. By applying this balance it is possible to include not only the operating energy use, but also the energy embodied in the building materials, construction and demolition and/or technical installations and thus evaluate true environmental impact of the building.

\subsubsection{Applied methodologies}

Eleven out of twelve methodologies are based on the annual balance, which could be expected. Firstly, due to the fact that most of the building energy simulation programs as the final result give the annual energy use of a building, and secondly it is also the most preferred balancing period among the ZEB definitions in the literature. Nevertheless, there is one - methodology 6 - that uses a monthly balance with a special requirement that out of total onsite renewable electricity generation only the amount that is equal to electricity use can be accounted in the balance. Other energy carriers cannot be balanced. The excess electricity generation is neglected in the calculations thus cannot offset future energy use of a building. Therefore, the achievement of a net ZEB is possible only in very special cases.

\subsection{Type of energy use}

According to the international standard EN 15603:2008 'Energy performance of buildings - overall energy use and definition of energy rating' [30] the energy rating calculation should obligatory include only the energy use that does not 'depend on the occupant behaviour, actual weather conditions and other actual (environment and indoor) conditions', in particular it means: heating, cooling and dehumidification, ventilation and humidification, hot water and lighting (for non-residential buildings). In practice, the methods 
A.J. Marszal et al. / Energy and Buildings 43 (2011) 971-979

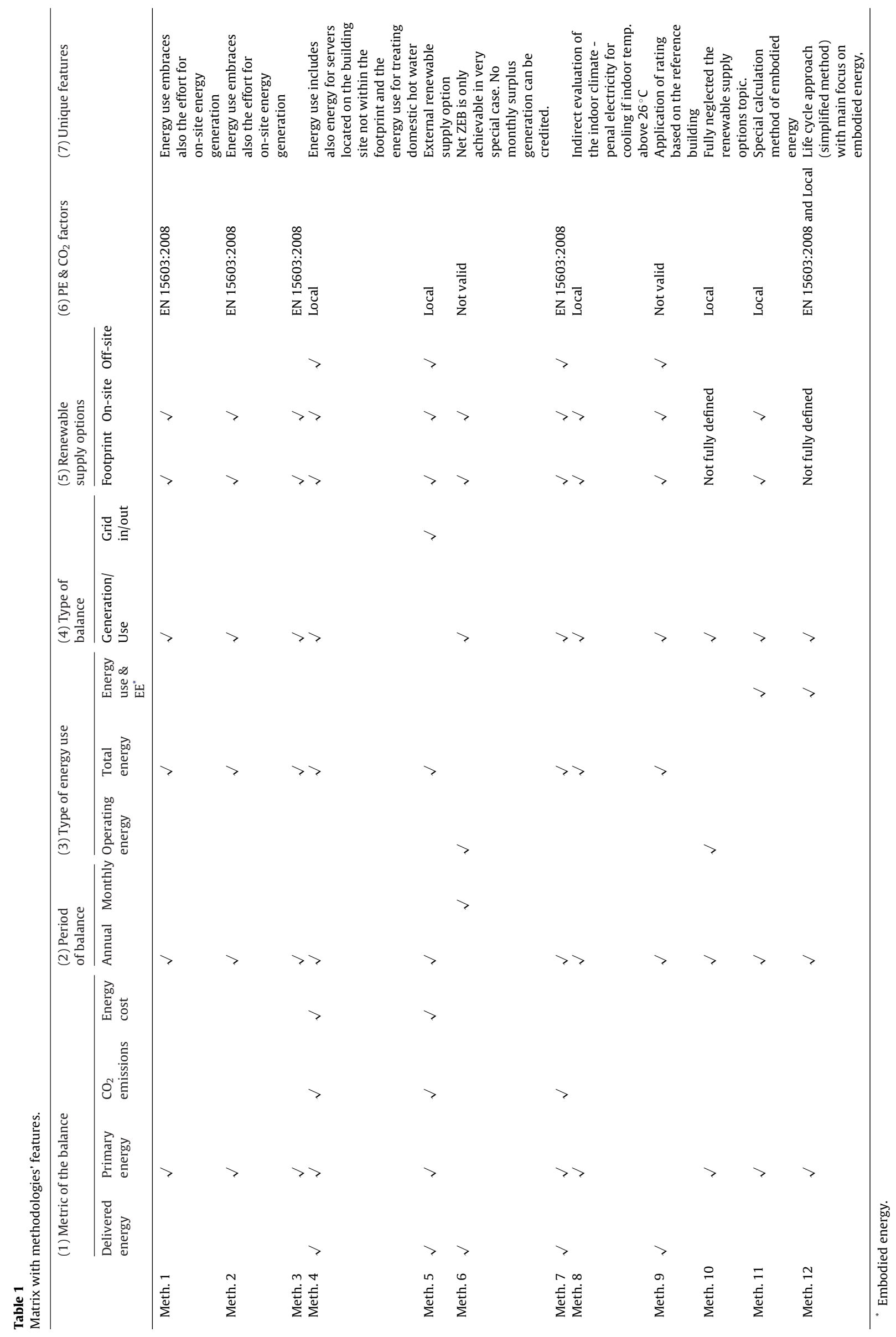


for computing the energy use of a building are very diverse and include various inputs.

\subsubsection{Literature review}

The publications from the 1970 s and 80 s' $^{\prime}[28,31,32]$ can be perceived as some of the first attempts towards zero energy buildings. At that time, when the biggest part of energy use in the buildings was mostly due to the thermal energy (space heating and/or domestic hot water (DHW) and/or cooling), the zero energy buildings were actually zero thermal buildings. An example could be the Zero Energy House in Denmark [28] where the authors state 'Zero Energy House is dimensioned to be self-sufficient in space heating and hot-water supply during normal climatic conditions in Denmark.' Another approach is presented by Iqbal [26] and Gilijamse [27] where the ZEB definition focuses only on electricity use. Hernandez and Kenny [19] suggest that the energy balance should not only be focus on the energy used by the building in the operation phase, but as well include the energy embodied with building construction and systems. However, it should be noted, that in the prevailing publications the type of energy use included in the balance is not specified $[4,13,16,19,25,29]$.

\subsubsection{Applied methodologies}

The wide diversity of the balance inputs is also represented by the calculation methodologies included in Table 1. Most of the calculation proposals take into account the total energy use of the building including both the building and user related energy, however, they also have their particularities with regard to input variables e.g. effort for on-site energy generation, penal electricity for overheating. The embodied energy is not commonly considered in the calculations of energy use of a building. However already two methodologies: 11 and 12 include it in their calculations. They have similar approach for accounting the energy embodied within building materials and systems yet with one difference. In the methodology 11 is a set limit of $25 \mathrm{kWh} / \mathrm{m}^{2}$ per year for the embodied energy under which it is neglected in the calculation but over which the difference between the actual embodied energy and the limit is taken into consideration in the calculations.

\subsection{Type of balance}

This issue is mostly relevant to grid connected ZEBs, because in this type of ZEBs there are two possible balances between: (1) the energy use and the renewable energy generation or (2) the energy delivered to the building and the energy feed in to the grid. As the result of both balances is the same in most cases (the exception is the fossil fuel Combined Heat and Power (CHP), which is not consider in the first balance but can be taken into consideration in the second one) the main difference is the period of application. The first balance is more applicable during the design phase of the building and the second to the monitoring phase. In the off-grid ZEBs the situation is clear the energy use has to be offset by the renewable energy generation.

\subsubsection{Literature review}

The net ZEB definitions from the existing literature are inconsistent in the type of balance that should be used. The most favoured is the balance between the energy needs or consumption and the renewable energy generation $[4,16,27,29]$. However, in the publications of Laustsen [25] and Mertz et al. [24] the energy balance reflects the status of the energy flows between the building and the energy infrastructure.

\subsubsection{Applied methodologies}

The study shows that the most accepted energy balance takes place between the energy use of a building and the renew- able energy generation. This approach is favoured within eleven methodologies. Only within one methodology the balance is based on the building grid interaction at the boundary of the building site, i.e. the overall energy delivered to the building from the utility grid has to be offset by the overall energy feed in to the grid.

\subsection{Renewable energy supply options}

The renewable sources can either be available on the site e.g. sun, wind or need to be transported to the site e.g. biomass. Therefore, in principle two renewable energy supply options exist: on-site supply and off-site supply, respectively.

\subsubsection{Literature review}

The majority of existing ZEB definitions in the literature fully neglect this topic with the exception of the recent EPBD recast [13]: 'The nearly zero or very low amount of energy required should be covered to a very significant extent by energy from renewable sources, including energy from renewable sources produced on-site or nearby'. Torcellini et al. [16] are one of the first that significantly contributed to this subject by proposing sub-options within above mentioned supply options. For the on-site supply they distinguish between supply within the building footprint and supply within the building site. As for the off-site supply, they indicate that building either uses renewable energy sources available off-site to produce energy on-site, or purchases off-site renewable energy sources. Moreover, Torcellini et al. [16] propose a ranking of preferred application of renewable energy sources, see Table 2 .

\subsubsection{Applied methodologies}

Most of the methodologies recognise two options for renewable supply, in particular building footprint and site. Four methodologies additionally acknowledge an option of off-site renewable supply. It can be understood as the investment in an off-site windmill and thus possibility to include the energy generated by the windmill into the energy balance of the building or as purchased green energy or $\mathrm{CO}_{2}$ credits that can offset the energy use. Yet, it should be noticed that there is some ambiguity in renewable supply options with regards to the biomass/biofuel CHP that in some cases is seen as on-site (focus on the actual location of the electricity generation) and in another as off-site renewable supply (focus of the fuel's origin).

Marszal et al. [33] attempt to graphically represent the possible renewable energy supply options suggested in different energy calculation methodologies, see Fig. 1. The authors emphasize that the graph should not be seen as a "hierarchy" of renewable supply options. It is merely a graphical representation of the different possible renewable supply options i.e. no option is understood as preferable for the time being. The graph is based on an overview of existing options applied in the international energy calculation methodologies. The five options (I-V) are ordered following the location of the energy supply option with respect to the building.

\subsection{Connection with the energy infrastructure}

The literature focuses either on off-grid or on-grid zero energy buildings. In both approaches the building is the energy consumer as well as the energy producer from renewable energy sources. The main difference is the connection to the energy infrastructure. As mentioned above, the proposed calculation methodologies reflect only the grid connected, net ZEBs thus this issue of grid connection is not discussed. 
Table 2

ZEB renewable energy supply option hierarchy. Source: Torcellini et al. [16].

\begin{tabular}{|c|c|c|}
\hline Option no. & ZEB supply-side options & Examples \\
\hline 0 & $\begin{array}{l}\text { Reduce site energy use through low-energy } \\
\text { building technologies }\end{array}$ & $\begin{array}{l}\text { Daylighting, high-efficiency HVAC equipment, natural } \\
\text { ventilation, evaporative cooling, etc. }\end{array}$ \\
\hline \multicolumn{3}{|c|}{ On-site supply options } \\
\hline 1 & $\begin{array}{l}\text { Use renewable energy sources available within } \\
\text { the building's footprint }\end{array}$ & PV, solar hot water, and wind located on the building \\
\hline 2 & $\begin{array}{l}\text { Use renewable energy sources available at the } \\
\text { site }\end{array}$ & $\begin{array}{l}\text { PV, solar hot water, low-impact hydro, and wind } \\
\text { located on-site, but not on the building }\end{array}$ \\
\hline \multicolumn{3}{|c|}{ Off-site supply options } \\
\hline 3 & $\begin{array}{l}\text { Use renewable energy sources available off site } \\
\text { to generate energy on site }\end{array}$ & $\begin{array}{l}\text { Biomass, wood pellets, ethanol, or biodiesel that can be } \\
\text { imported from off site, or waste streams from on-site } \\
\text { processes that can be used on-site to generate } \\
\text { electricity and heat }\end{array}$ \\
\hline 4 & Purchase off-site renewable energy sources & $\begin{array}{l}\text { Utility-based wind, PV, emissions credits, or other } \\
\text { "green" purchasing options. Hydroelectric is } \\
\text { sometimes considered }\end{array}$ \\
\hline
\end{tabular}

\subsubsection{Literature review}

The off-grid ZEB is not connected to any utility grid and hence needs to use some electricity storage system for periods with peak loads. In the literature this type of ZEB is also named 'self-sufficient', 'autonomous' or 'stand alone', an exemplary definition could be: 'Zero Stand Alone Buildings are buildings that do not require connection to the grid or only as a backup. Stand alone buildings can autonomously supply themselves with energy, as they have the capacity to store energy for night-time or wintertime use', Laustsen [25]. Further examples of the off-grid ZEB projects and/or definitions are given by Vale and Vale [18], Iqbal [26], Stahl et al. [34], Voss et al. [35], Platell and Dudzik [36] and Kramer et al. [37]. The on-grid ZEB, also known as 'net zero energy', 'grid connected' or 'grid integrated' [4,16,25-27,29,38], has the connection to one or more energy infrastructures; electricity grid, district heating and cooling system, gas pipe network, biomass and biofuels distribution networks. Therefore, it has the possibility of both purchasing energy from the grid and feeding in excess energy to the grid and thus avoiding on-site electricity storage. An example of grid connected ZEB definition: 'Zero Net Energy Buildings are buildings that over a year are neutral, meaning that they deliver as much energy to the supply grids as they use from the grids. Seen in these terms they do not need any fossil fuel for heating, cooling, lighting or other energy uses although they sometimes draw energy from the grid', [25].

The issue of large storage capacity, backup generators, energy losses due to storing or converting energy and oversized renewable energy producing system in autonomous ZEB result in lack of global implication of the off-grid ZEB [16,17]. Vale and Vale [18] take both the practical and philosophical approach to investigate the autonomous versus grid connected houses in UK and come to the conclusions: 'In the United Kingdom, with its dense population and its national electricity grid, it would make no sense to abandon the resources that have been put into creating the gird, and replace them with new resources in the form of batteries in order to achieve a symbolic self-sufficiency.'

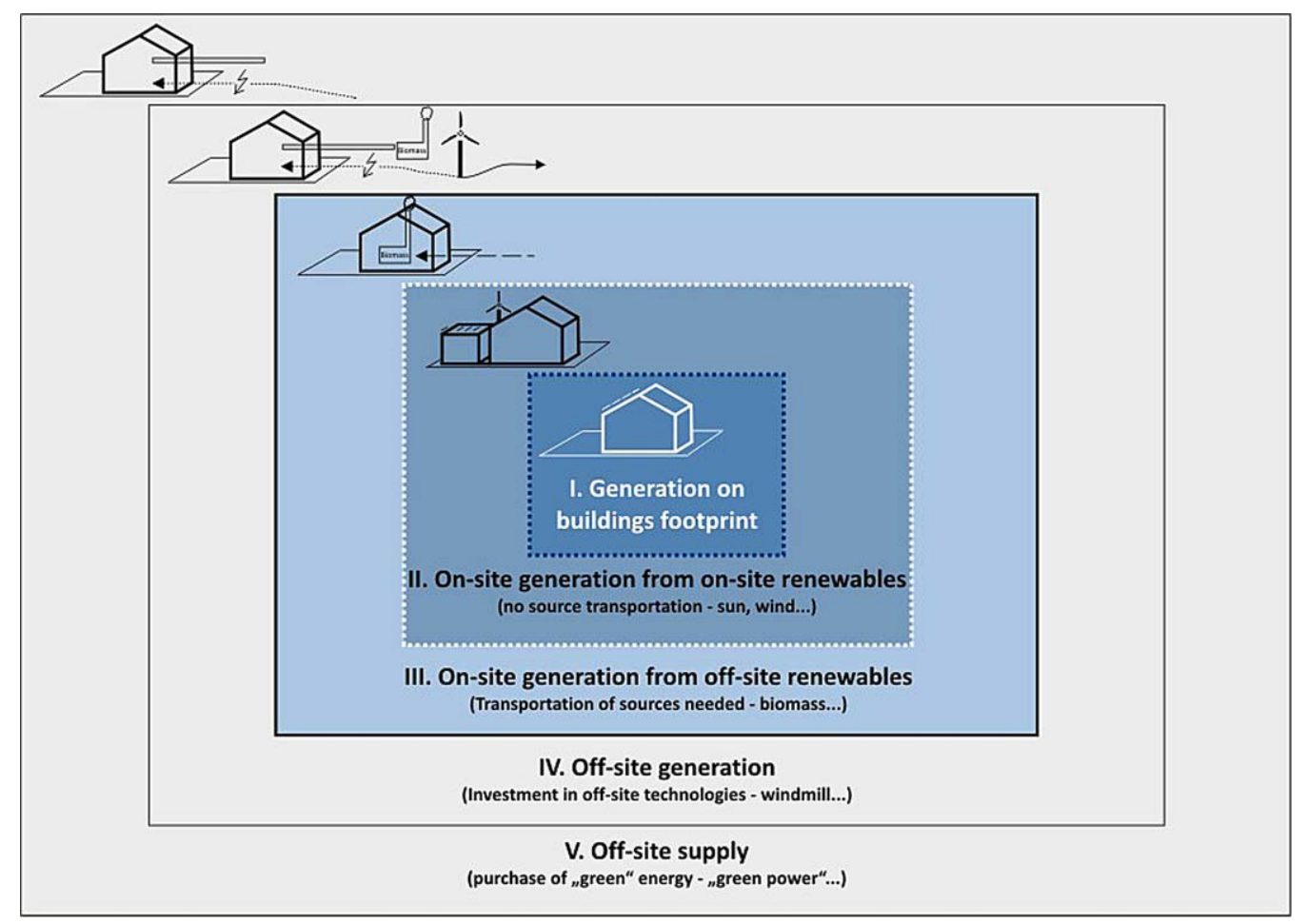

Source: Marszal et al. [33].

Fig. 1. Overview of possible renewable supply options. 


\subsection{Requirements}

Nowadays, buildings have to meet a number of requirements before being constructed. The requirements that significantly can influence the design and thus the 'quality' of ZEBs are (1) energy efficiency requirements and (2) indoor climate requirements and in the case of grid connected ZEBs (3) building-grid interaction requirements. Therefore, only those are further discussed in the paper.

The calculation methodologies presented in Table 1 are focused only on indicating possible energy balance calculations hence they do not include any requirements and therefore are not analysed in this chapter.

\subsubsection{Energy efficiency requirements}

2.7.1.1. Literature review. As mentioned by Laustsen [25] in principle a Zero Energy Building can be a traditional building, which is supplied with a very large solar collector and a solar photo voltage systems. If these systems deliver more energy over a year than the use in the building the goal of zero energy is met. This approach towards ZEBs is very uncommon. Nevertheless, only few out of the reviewed ZEB definitions emphasise the importance of employment of energy efficiency measures before utilization of renewable energy sources: Torcellini et al. [16]: '(ZEB) is a residential or commercial building with greatly reduced energy needs through efficiency gains such that the balance of energy needs can be supplied with renewable technologies'; Iqbal [26]: Zero energy home is the term used for a home that optimally combines commercially available renewable energy technology with the state of the art energy efficiency construction techniques.'; The Danish ZEB demonstration project BOLIG $+[1]$ is defined by five dogmas, that together can be perceived as a project's ZEB definition. Already, with the first dogma, it is emphasized the building have to fulfil the requirements for the low energy class 1 [39], before applying of the renewable energy technologies.

\subsubsection{Indoor climate requirements}

2.7.2.1. Literature review. In the current ZEB definitions the issue of indoor climate requirements is not well developed and discussed mostly in favour of the energy issue debates. Only few of the analysed ZEB definitions look upon this topic as for example - the Active house concept [5] and the BOLIG+ concept [1]. In the first project the indoor climate requirements relate mainly to daylight, fresh air and choice of materials. In the second case the requirements are more demanding and by a good and healthy indoor climate it is understood: utilization of daylight and sufficient artificial light control, sufficient atmospheric indoor climate, temperature and air quality, healthy materials with good influence on acoustics and sound.

\subsubsection{Building-grid interaction requirements}

2.7.3.1. Literature review. The existing net ZEB definitions mostly neglect this topic. It is mentioned in the definitions that the building is connected the energy grid, however, with no details describing the interaction. The only attention given to this issue is presented by Kilkis [20]. The author indicates that due to different energy qualities between exported and imported energy, the utility grid is often in worst position than the building; therefore he proposes a net zero exergy building definition that better accounts for different energy qualities. Among the five dogmas describing the Bolig+ concept [1] one sets the requirement for building-grid interaction. It is stated that energy feed back to the grid has to have the same usability as the energy taken from the grid.

\section{Verification of the proposed calculation methodologies}

\subsection{Description of the study case}

The BOLIG+ is a net ZEB demonstration project of a $10 / 6$ storey multifamily building with 60 apartments located in Aalborg, Denmark [1]. It has been used to verify the applicability of the calculation methodologies proposed in the Table 1 , and to identify possible difficulties in performing the calculations. BOLIG+'s energy producing system is photovoltaic installation (PV) in combination with a photovoltaic/solar thermal collector $(\mathrm{PV} / \mathrm{T})$ and a solar heat pump. The PV and PV/T is placed on the building roof and facade. The building is $7000 \mathrm{~m}^{2}$ with the following energy demand:

- Domestic hot water: $14.4 \mathrm{kWh} / \mathrm{m}^{2}\left(52 \mathrm{MJ} / \mathrm{m}^{2}\right)$ per year

- Space heating: $13.7 \mathrm{kWh} / \mathrm{m}^{2}\left(49 \mathrm{MJ} / \mathrm{m}^{2}\right)$ per year

- Electricity for operating the building: $7.6 \mathrm{kWh} / \mathrm{m}^{2}$ per year

- Electricity for household: $15.0 \mathrm{kWh} / \mathrm{m}^{2}$ per year

- PV electricity production: $22.6 \mathrm{kWh} / \mathrm{m}^{2}$ per year

- PV/T thermal production: $8.3 \mathrm{kWh} / \mathrm{m}^{2}\left(30 \mathrm{MJ} / \mathrm{m}^{2}\right)$ per year

- Heat pump thermal output: $20.0 \mathrm{kWh} / \mathrm{m}^{2}\left(72 \mathrm{MJ} / \mathrm{m}^{2}\right)$ per year

The thermal production for the $\mathrm{PV} / \mathrm{T}$ is perceived as an energy efficiency measure that reduces the thermal demand of the building Thus, it is not included as renewable energy generation within the calculations. The BOLIG+ exchanges only electricity with the utility grid, however, as the building is still in the design phase and exact electricity flows between the building and the electricity grid are un-known, it is assumed to be $67 \%$ of the total electricity production [40].

\subsection{Results}

As it can be seen in Table 3, the results are quite consistent: if the proposed net ZEB methodology has a unique input variable or very special procedure to calculate the 'zero' balance then the balance is not fulfilled. For the methodology 1 and 2 it is the extra energy use that is used for generating energy on-site, and for the methodology 4 it is the additional energy used for treating the water. In the case of methodology 11 and 12 the calculations could not be finished due to lack of embodied energy data in the project.

As the BOLIG+ is a full electrical house - one energy carrier the correspondence between different units is good. The exception is the balance with energy cost as the unit. This is caused by the fact that the feed-in tariff is much lower than the purchase tariff. This parameter depends very much on the national context and the national approach towards distributed, small energy plants or sometimes the individual, private agreement between the building owner and the utility grid. Thus, the results have very national/regional meaning.

Table 3

Overview of the results of fulfillment of the proposed calculation methodologies: ' $\sqrt{ }$ ' fulfilled, '-' not fulfilled, ' $\sqrt{ }$-' partly fulfilled.

\begin{tabular}{lllll} 
& Delivered energy & Primary energy & $\mathrm{CO}_{2}$ emissions & Energy cost \\
\hline Meth. 1 & & - & & \\
Meth. 2 & & - & & \\
Meth. 3 & & $\sqrt{ }$ & - \\
Meth. 4 & - & $\sqrt{ }$ & \\
Meth. 5 & $\sqrt{ }$ & & $\sqrt{ }$ & \\
Meth. 6 & $\sqrt{ }-$ & $\sqrt{ }$ & \\
Meth. 7 & $\sqrt{ }$ & $\sqrt{ }$ & \\
Meth. 8 & & $\sqrt{ }$ & \\
Meth. 9 & $\sqrt{ }$ & & \\
Meth. 10 & & & \\
Meth. 11 & Due to lack of date impossible to complete & \\
Meth. 12 & Due to lack of date impossible to complete & \\
\hline
\end{tabular}


The special status of the methodology 6 reflects its unique feature, namely the monthly balance. In this case for eight months, from March to October, the 'zero' balance is achieved. However for the rest of the year (November-February) the energy use of the building is higher than the on-site renewable energy generation from PV. This result indicates very well the variable ability of renewable energy sources, in particular sun, and the periods when the building needs the energy support from the utility grid.

In the BOLIG+ case the division between different renewable supply options is not applicable, since as mentioned, before the PV and $\mathrm{PV} / \mathrm{T}$ yield is placed within building footprint.

\section{Discussion}

The review of the existing ZEB definitions and the proposals for calculation methodologies indicates complexity of the concept, lack of common agreement as well as emphasizes the key issues that should be deliberated and clarified before further deployment of the ZEBs. The following chapter argues over possible answers for the questions with underlining their pros and cons.

The first and probably by far the most important point on the ZEB agenda is the metric for the balance. The energy unit is acknowledged by most ZEB definitions and as well as by the proposed calculation methodologies. It can be chosen between the delivered or the primary energy as the indicator for the balance. The delivered energy is the easiest unit to implement and as well to understand for most of the people. However, it has two major drawbacks: firstly, conversion and transportation losses are not accounted and secondly the quality of different kinds of energy is fully neglected. The only case for adopting this metric is for the ZEB using only one energy carrier e.g. full-electrical ZEB. Hence, most frequently applied unit is primary energy. It allows taking into consideration the difference in the generation and distribution of $1 \mathrm{~kW}$ of electricity and $1 \mathrm{~kW}$ of heat or natural gas and thus express better the actual building energy use. However, it must be noted that there are also some issues related to primary energy balance, in particular, (1) the changing with time primary energy factors as the result of changing characteristic of the energy infrastructure and (2) the underestimation of renewable energy sources: hydro, wind, sun. The second issue is described by Segers [41]. The author argues that the renewable energy technologies e.g. photovoltaic, hydropower are discriminated when using primary energy as the metric, since 1 unit of electricity produced with the conventional way, e.g. thermal power plant, requires usually 2-3 units of primary energy, whereas 1 unit of hydro electricity requires 1 unit of primary energy. Therefore, he proposes the 'substitution method' where the renewable energy sources are compared with typically conventional energy sources by the use of suitable conversion factor. This approach is also adopted by most of the proposed calculation methodologies, where the energy generated by the on-site renewable technologies e.g. photovoltaic is perceived as avoided energy from utility grids that usually use conventional energy sources. As indicated by the definitions and methodologies review the second favoured metric is the carbon equivalent emissions. The main reason could be the fact that globally the discussion on climate change mainly refers to the national and/or international emissions reductions targets and further actions to reduce the GHG emissions [42]. On the other hand, in practice in the building community the buildings are more commonly evaluated and certificated based on energy performance rather than on emissions performance. Other crediting options, depicted in the literature and used in the calculation methodologies, are the energy costs or exergy. The first option could be a very 'catchy' advertisement of the ZEB concept, understandable for wide audience, however, with a major drawback of being very unstable. Although, exergy as metric for calculation allows to evaluate the complete environmental impact of a building [20], it is not a well understood outside the academic community and thus difficult for the building industry and policy makers to correctly relate to such thermodynamic concept. Moreover, Sartori et al. [43] indicate that for the grid connected ZEBs, with adopting the suitable metric for the balance, it is also important to address the future changes in the energy infrastructure i.e. the increasing integration of renewable energy sources and thus changes of grid's primary energy factors.

For the energy use of a building a year is the most particular and accepted calculation period. It is also the most favoured one among the existing ZEB definitions and the proposed calculation methodologies. As the annual energy use in the building can differ from year to year due to many reasons i.e. stronger and longer winters, warmer summers or new occupants an alternative for the annual balance can be a balance over e.g. 50 years of building operation. This approach may consider an outlook on the grid of the future (e.g. decreasing primary energy factor with time). Another option, not very popular within the building community, however, adopted by methodology 6 , is the sub-yearly balance i.e. seasonal or monthly. By using these balancing periods the energy producing systems are dimensioned to better match the actual energy demand, but on the other hand they can be often oversized. Moreover, it is more difficult to achieve zero balance than in the case of annual balance, since the seasonal discrepancy between energy demand and renewable energy generation. An alternative balancing period, that includes also the embodied energy in the building materials and/or technical systems and/or construction and demolition phases and/or recycling of the materials, is entire life cycle of a building. By adopting this option, it is a key issue to define the boundaries of the buildings life cycle. The possible approaches are the 'Cradle to Cradle', 'Cradle to Grave', 'Cradle to Gate' and 'Gate to Grave' [47].

The issue of what types of energy to include in the annual energy balance of a building has been discussed globally for decades and yet no agreement has been reached. The same question arises for the energy balance of ZEB again with no clear answer. Most of the existing ZEB definitions do not specify which energy type is included in the balance. The methodologies on the other hand, give rather clear message: total operating energy use of a building. The energy rating and certification methods of a building account only the operating energy related to the building and the same practice is followed by many European building codes [30,33]. The main reason for neglecting the user related energy use in the calculation methods is due to its high uncertainty and lack of sufficient data/inputs. However, as studies of occupant behaviour indicate there is a great potential for reducing overall energy use and improving building economy by motivating energy efficient behaviour $[44,45]$. This fact becomes more important when taking into consideration that energy efficient technologies are constantly improving and decreasing building related operating energy use. Hence, the user related energy becomes an important part of the total energy use of a building. Moreover, seen from the utility grid perspective, the case for gird connected ZEBs, the division between building and user related energy is irrelevant, only the total use counts [46]. Another type of energy that can be considered as the input in the energy balance of ZEB is the embodied energy. As the literature review indicates the result of e.g. greater use of energy-intensive materials, larger buildings and more frequent refurbishments the energy embodied in the building materials and technical systems is growing $[47,48]$. Moreover, with further reduction of operating energy the share and importance of the embodied energy in the life cycle energy of a building will increase. However, similarly as with user related energy use there is a lack of accurate and reliable values/inputs and thus a lack of interest in calculation and analysis of the embodied energy [47].

The renewable supply options are still under discussion with no international agreement and with not clear answer within the ZEB definitions and the proposed energy calculation methodolo- 
gies. Probably, common agreement never will be reached due to very different national contexts and realities. Most commonly the renewable energy technologies are placed within the building footprint or site, but other options i.e. purchase of $\mathrm{CO}_{2}$ credits or green power from nearby/local utility grid are also adopted for reaching ZEB status. Torcellini et al. [16] suggest the hierarchy of renewable supply options, see Table 2 . However, if purchasing $\mathrm{CO}_{2}$ credits is a better solution than installing PV on the roof with regards to economy, then is the hierarchy valid?

In the analysis of the existing ZEB definitions a very similar path to achieve ZEB can be noticed. Firstly, the reduction of energy demand using energy efficient measures and secondly the utilization of renewable energy sources to supply the remaining energy demand. Energy efficiency is usually available for the life of the building; however, efficiency measures must have good persistence and should be "checked" to make sure they continue to save energy. It is almost always easier to save energy than to produce energy and the above strategy is the most logical approach to reach ZEB. In order to ensure that Zero Energy Buildings also are very energy efficient buildings a fixed value of maximum allowed energy use could be a good solution in combination with energy efficiency requirements for specific components and technologies. Mowing towards more specific criteria, the indoor climate requirements could also be part of the ZEB definition. On the one hand, it would be very beneficial from a general point of view that all ZEB would use the same requirements with regard to energy efficiency and indoor climate and thus it would be much easier to evaluate and compare ZEBs from different locations worldwide. On the other hand, giving so detailed criteria in the ZEB definition could significantly limit its usefulness in many cases. Since, different values can be used depending on building type, location, applied standard and local climate conditions.

The building-grid interaction requirements are only relevant for the grid-connected ZEB that exchange energy with the energy infrastructure. As mentioned before, in most of the ZEB definitions this topic is commonly neglected and the utility grid is perceived as an unlimited energy storage with no losses. However, this approach is currently changing and more research focus on investigating the interaction that would be a benefit for the building and as well as for the energy infrastructure $[12,40,46,49,50]$. The biggest attention is given to the interaction with the electricity grid due to only few cases of ZEB in Austria that exchange heat with the district heating grid. Moreover, the possibility to exchange the heat is feasible only within few European countries. The grid-building interaction and associated requirements are quite a challenge to define, since the approaches for this interaction are very different depending on whether it is seen from grid or building perspective and the on national context. Two indexes were defined to characterize the building-grid interaction looking from the building perspective. This include in particular, the load match index that describes how much of the demand is covered by the on-site generation thus how much stress is put on the grid, and the grid interaction index, that describes the fluctuation of the energy exchange of the ZEB with the electricity grid $[46,49,50]$. The building-grid interaction seen from the Danish grid perspective has been analysed by Lund et al. [40] by introducing the mismatch compensation factor. It is defined as the relation between the capacity of the PV or similar RES installation for which the annual import and export of electricity is the same and the capacity of the installation for which the economic value of annual import and export of electricity is the same. Unfortunately, the results of the building-grid interaction analysis depend on many measures i.e. the grid characteristic, location, type and load profile of the building, resolution of the analysis. Thus in some cases the adaptation of specific measures will result in a high ZEB load match and positive contribution to the grid, but for other cases the same measures will favourable.
Economy is an additional issue that currently is left aside in the ZEB definition literature but is of a great importance in practice and for the future wide implementation of the concept. To date, most of the ZEBs are demonstration projects, where economy often is not a pivotal role. Unfortunately, in everyday life for an average person the costs commonly are the decision making measure. Thus, the ZEB concept and its definitions should be developed to attract the attention of a regular building owner. A possible way could be use the life cycle as the period of the balance. By applying this approach, it is possible to present that although the ZEB investment costs are higher than for a regular house the operation costs are lower, due to lower energy use and on-site renewable energy generation. Therefore, the overall costs of a ZEB versus a regular building should be in favour of the ZEBs.

Finally, the discussion of ZEB concept comes to the point: what about the existing buildings, are they also taken into consideration in the development of new ZEB definition? Naturally, they should be included, since the existing buildings are responsible for the current energy use of the building sector, and therefore, have a great potential for improvements. Unfortunately, the renovation is much more challenging task than the construction of a new building, with a number of aspects and obstacles that significantly can narrow down the possible technical solutions especially in the dense city area or for multi-storey buildings. One of the major issues, with regards to ZEBs in the renovation sector, is the renewable energy supply options. Often the building context and its location do not allow to design the building only based on PV as the solely renewable energy source; therefore another source of renewable energy has to be applied e.g. biomass CHP [51]. So, if ZEB definitions will include any requirements, they should be different for existing and newly constructed buildings in order to make it feasible for both cases.

\section{Summary/conclusions}

The attention given to the Zero Energy Building concept increased during the last years. Many countries have already established ZEBs as their future building energy target. Among different strategies for decreasing the energy consumption in the building sector, ZEBs have the promising potential to significantly reduce the energy use and as well to increase the overall share of renewable energy. However, in order not to fall short of expectation, there is a need for commonly agreed ZEB definition framework and a robust 'zero' calculation methodology. This framework should allow for a variety of solution sets and not focus only on PV based solution sets, as this strategy is mainly addressing small and new buildings.

This paper presented a literature review of ZEB definitions and proposed energy calculation methodologies for ZEBs. The ZEB definitions are expressed with a wide range of terms and phrases in the literature whereas the calculation methodologies are more consistent and have a common framework.

Based on the literature review, the paper identified and presented a set of parameters that differ between ZEB definitions and which should be elaborated before defining a harmonized ZEB understanding. The study indicated that the metric, the period and the types of energy included in the energy balance together with the renewable energy supply options, the connection to the energy infrastructure and energy efficiency, the indoor climate and the building-grid interaction requirements are the most important issues. Moreover, this paper discussed possible solutions for the implementation of the listed parameters and indicated their advantages and disadvantages. However, the goal of the paper was not to give one final answer to the questions e.g. which metric should be applied or which type of energy include in the energy balance and thus to formulate a new definition of the ZEB concept. The paper 
objective was to present how different the understandings of the same fairly simple concept already are.

\section{Acknowledgements}

The work presented in this paper has been developed in the context of the joint IEA SHC Task40/ECBCS Annex52: Towards Net Zero Energy Solar Buildings. The authors would like to thank all participants of Subtask A and especially: Sonja Geier, Monika Hall, Shanti Pless, José A. Candanedo, Søren Østergaard Jensen for supplying the proposals for the net ZEB calculation methodologies.

\section{References}

[1] The BOLIG+ project, http://www.boligplus.org/(in Danish) (accessed 19.11.10).

[2] V.Åkarp, http://greenlineblog.com/2009/02/villa-karp-a-positive-net-energyhouse-in-malm-sweden/ (accessed 19.11.10).

[3] The International Energy Agency (IEA) Net Zero Energy Buildings Database, http://iea40.buildinggreen.com/index.cfm (accessed 19.11.10).

[4] M. Noguchi, A. Athienitis, V. Delisle, J. Ayoub, B. Berneche, Net Zero Energy Homes of the Future: A Case Study of the ÉcoTerraTM House in Canada, in: Renewable Energy Congress, Glasgow, Scotland, July, 2008.

[5] The Active House project, http://www.activehouse.info/ (accessed 19.11.10).

[6] M. Heinze, K. Voss, Goal zero energy building - exemplary experience based on the solar estate Solarsiedlung Freiburg am Schlierberg, Germany, Journal of Green Building 4 (4) (2009).

[7] E. Musall, T. Weiss, A. Lenoir, K. Voss, F. Garde, M. Donn, Net Zero Energy Solar Buildings: An Overview and Analysis on Worldwide Building Projects, in: EuroSun Conference 2010, Graz, Austria, 2010 (under review).

[8] The IEA SHC Task 40/ECBCS Annex 52 'Towards Net Zero Energy Solar Buildings (NZEBs)', http://www.iea-shc.org/task40/index.html (accessed 19.11.10).

[9] The Strategic Research Centre on Zero Energy Buildings, http://www.zeb.aau.dk/ (accessed 19.11.10).

[10] The Research Centre on Zero Emission Buildings (ZEB), www.zeb.no (accessed 19.11.10).

[11] Zero Carbon Hub, http://www.zerocarbonhub.org/ (accessed 19.11.10).

[12] D. Crawley, S. Pless, P. Torcellini, Getting to net zero, ASHRAE Journal 51 (9) (2009) 18-25.

[13] The Directive 2010/31/EU of the European Parliament and of the Council of 19 May 2010 on the energy performance of buildings, Official Journal of the European Union, 53, 2010.

[14] U.S. Green Building Council (USGBC), Leadership in Energy and Environmental Design (LEED) Green Building Rating System, http://www.usgbc.org/DisplayPage.aspx?CategoryID=19 (accessed 19.11.10).

[15] BRE Environmental Assessment Method (BREEAM), http://www.breeam.org/ (accessed 19.11.10)

[16] P. Torcellini, S. Pless, M. Deru, D. Crawley, Zero Energy Buildings: A Critical Look at the Definition, in: ACEEE Summer Stud, Pacific Grove, California, USA, 2006.

[17] K. Voss, What is Really New about Zero-Energy Homes? in: 12th International Conference on Passive Houses, Nuremberg, Germany, 2008.

[18] B. Vale, R. Vale, The New Autonomous House: Design and Planning for Sustainability, Thames \& Hudson Ltd, 2002.

[19] P. Hernandez, P. Kenny, From net energy to zero energy buildings: defining life cycle zero energy buildings (LC-ZEB) Energy and Buildings 42 (6) (2010) $815-821$.

[20] S. Kilkis, A New Metric for Net-zero Carbon Buildings, in: Energy Sustainability Conference, Long Beach, California, 2007.

[21] P.A. Torcellini, D.B. Crawley, Understanding zero-energy buildings, ASHRAE Journal 48 (9) (2006) 62-69.

[22] NAHB Research Center, The Potential Impact of Zero Energy Homes, NAHB Research Center, Maryland, USA, 2006.

[23] Center for the Built Environment (CBE), Centerline, Getting to Zero-energy Buildings, USA, 2008.

[24] G.A. Mertz, G.S. Raffio, K. Kissock, Cost Optimization of Net-zero Energy House, in: Energy Sustainability, California, USA, 2007.
[25] J. Laustsen, Energy Efficiency Requirements in Building Codes, in: Energy Efficiency Policies for New Buildings, OECD/IEA, Paris, 2008.

[26] M.T. Iqbal, A feasibility study of a zero energy home in Newfoundland, Renewable Energy 29 (2) (2004) 277-289.

[27] W. Gilijamse, Zero-energy houses in the Netherlands, in: Building Simulation '95, Madison, Wisconsin, USA, 1995.

[28] T.V. Esbensen, V. Korsgaard, Dimensioning of the solar heating system in the zero energy house in Denmark, Solar Energy 19 (2) (1977) 195-199.

[29] S. Rosta, R. Hurt, R. Boehm, M.J. Hale, Performance of a zero-energy house, Journal of Solar Energy Engineering Transactions of the ASME 130 (2) (2008) 0210061-0210064.

[30] CEN, EN 15603:2008 'Energy performance of buildings - overall energy use and definition of energy rating', 2008 .

[31] R.W. Besant, R.S. Dumont, G. Schoenau, The Saskatchewan conservation house: some preliminary performance results, Energy and Buildings 2 (2) (1979) 163-174.

[32] T. Saitoh, H. Matsuhashi, T. Ono, An energy-independent house combining solar thermal and sky radiation energies, Solar Energy 35 (6) (1985) 541-547.

[33] A.J. Marszal, J.S. Bourrelle, E. Musall, P. Heiselberg, A. Gustavsen, K. Voss, Net Zero Energy Buildings - Calculation Methodologies versus National Building Codes, in: EuroSun Conference, Graz, Austria, 2010.

[34] W. Stahl, K. Voss, A. Goetzberger, The self-sufficient solar house Freiburg, Solar Energy 52 (1) (1994) 111-125.

[35] K. Voss, A. Goetzberger, G. Bopp, A. Häberle, A. Heinzel, H. Lehmberg, The selfsufficient solar house in Freiburg - results of 3 years of operation, Solar Energy $58(1-3)(1996) 17-23$.

[36] P. Platell, D.A. Dudzik, Zero Energy Houses Geoexchange, Solar CHP, and Low Energy Building Approach, in: Energy Sustainability Conference, Long Beach, California, 2007.

[37] J. Kramer, A. Krothapalli, B. Greska, The Off-grid Zero Emission Building, in: Energy Sustainability Conference, Long Beach, California, 2007.

[38] D.S. Paker, M. Thomas, T. Merrigan, On the Path to Zero Energy Homes, National Renewable Energy Laboratory, DOE/GO-102001-1287, 2001.

[39] Building Regulations 2008 (BR08), The Danish Ministry of Economic and Business Affairs Danish Enterprise and Construction Authority, 2007.

[40] H. Lund, A. Marszal, P. Heiselberg, Zero Energy Buildings and Mismatch Compensation Factors, Energy and Buildings, accepted for publication.

[41] R. Segers, Three options to calculate the percentage renewable energy: an example for a EU policy debate, Energy Policy 36 (9) (2008) 3243-3248.

[42] C. Wilford, M. Ramos, Zero Carbon Compendium Who's Doing What in Housing Worldwide, NHBC Foundation, Amsterdam, 2009.

[43] I. Sartori, A. Napolitano, A.J. Marszal, S. Pless, P. Torcellini, K. Voss, Criteria for Definition of Net Zero Energy Buildings, in: EuroSun Conference, Graz, Austria, 2010.

[44] G. Peschiera, J.E. Taylor, J.A. Siegel, Response-relapse patterns of building occupant electricity consumption following exposure to personal, contextualized and occupant peer network utilization data, Energy and Buildings 42 (8) (2010) $1329-1336$.

[45] O.T. Masoso, L.J. Grobler, The dark side of occupants' behaviour on building energy use, Energy and Buildings 42 (2) (2010) 173-177.

[46] K. Voss, I. Sartori, A. Napolitano, S. Geier, H. Gonzalves, M. Hall, P. Heiselberg7, J. Widén, J.A. Candanedo, E. Musall, B. Karlsson, P. Torcellin, Load Mathing and Grid Interaction of Net Zero Energy Buildings, in: EuroSun Conference, Graz, Austria, 2010.

[47] M.K. Dixit, J.L. Fernández-Solís, S. Lavy, C.H. Culp, Identification of parameters for embodied energy measurement: a literature review, Energy and Buildings $42(8)(2010) 1238-1247$.

[48] Y.L. Langston, C.A. Langston, Reliability of building embodied energy modeling: an analysis of 30 Melbourne case studies, Construction Management and Economics 26 (2) (2008) 147-160.

[49] J. Widén, E. Wäckelgård, P.D. Lund, Options for improving the load matching capability of distributed photovoltaics: methodology and application to highlatitude data, Solar Energy 83 (11) (2009) 1953-1966.

[50] R. Baetens, R. De Coninck, L. Helsen, D. Saelens, The impact of domestic load profiles on the grid interaction of building integrated photovoltaic (BIPV) systems in extremely low-energy dwellings, in: Renewable Energy Research Conference, Trondheim, Norway, 2010.

[51] F. Kagerer, S. Herkel, Concepts for Net Zero Energy Buildings in Refurbishment Projects, in: EuroSun Conference, Graz, Austria, 2010 